Case Report

\title{
Lichen Planus Induced by Pegylated Interferon Alfa-2a Therapy in a Patient Monitored for Delta Hepatitis
}

\author{
Safak Kaya, ${ }^{1}$ Eyup Arslan, ${ }^{2}$ Birol Baysal, ${ }^{3}$ Sule Nergiz Baykara, ${ }^{4}$ \\ Ozlem Ceren Uzun, ${ }^{5}$ and Sehmuz Kaya ${ }^{6}$ \\ ${ }^{1}$ Department of Infectious Diseases, Gazi Yasargil Training and Research Hospital, Turkey \\ ${ }^{2}$ Department of Infectious Diseases, Selahaddin Eyyubi State Hospital, Turkey \\ ${ }^{3}$ Department of Gastroenterology, Bezmialem University Faculty of Medicine, Turkey \\ ${ }^{4}$ Department of Dermatology, Selahaddin Eyyubi State Hospital, Turkey \\ ${ }^{5}$ Department of Pathology, Selahaddin Eyyubi State Hospital, Turkey \\ ${ }^{6}$ Department of Orthopedics Surgery, Van Training and Research Hospital, Turkey \\ Correspondence should be addressed to Safak Kaya; ksafak76@gmail.com
}

Received 10 January 2015; Accepted 24 February 2015

Academic Editor: Pere Domingo

Copyright (C) 2015 Safak Kaya et al. This is an open access article distributed under the Creative Commons Attribution License, which permits unrestricted use, distribution, and reproduction in any medium, provided the original work is properly cited.

Interferons are used for treatment of chronic hepatitis B. They can induce or exacerbate some skin disorders, such as lichen planus. In this study, as we know, we presented the first case developing lichen planus while receiving interferon treatment due to delta hepatitis. A 31-year-old male patient presented to our outpatient clinic with HBsAg positivity. With his analyses, HBV DNA was negative, anti-delta total was positive, ALT was $72 \mathrm{U} / \mathrm{L}$ (upper limit $41 \mathrm{U} / \mathrm{L}$ ), and platelet was $119000 / \mathrm{mm}^{3}$. He was therefore started on subcutaneous pegylated interferon alfa-2a therapy at $180 \mathrm{mcg} /$ week for delta hepatitis. At month 4 of therapy, the patient developed diffuse eroded lace-like lesions in oral mucosa, white plaques on lips, and itchy papular lesions in the hands and feet. Lichen planus was considered by the dermatology clinic and topical treatment (mometasone furoate) was given. The lesions persisted at month 5 of therapy and biopsy samples were obtained from oral mucosal lesions and interferon dose was reduced to $135 \mathrm{mcg} /$ week. Biopsy demonstrated nonkeratinized stratified squamous epithelium; epithelial acanthosis, spongiosis, and apoptotic bodies were observed in the epidermis and therefore lichen planus was considered. At month 6 of therapy, lesions did not improve and even progressed and interferon treatment was therefore discontinued.

\section{Introduction}

Lichen planus (LP) is an inflammatory disease in which chronic keratosis occurs in the skin or mucous membranes or both. Skin lesions are located in the extremities, genitalia, nails, face, and scalp. Mucous membrane lesions are located in the oral cavity, nasal mucous membranes, throat, esophagus, stomach, bladder, vagina, and glans penis [1]. The incidence in the general population is reported to be $1 \%$ [2]. Interferons are used for treatment of chronic hepatitis $\mathrm{B}, \mathrm{C}$, and D. They can induce or exacerbate some skin disorders, such as lichen planus, with cytokine cascades [3]. However, there is an association between chronic hepatitis with LP. The first report indicating the association between chronic liver diseases and LP was informed in 1978 [4]. In the literature, there are many reports related to lichen planus development in patients receiving interferon therapy due to chronic hepatitis $\mathrm{C}$. In this study, as we know, we presented the first case developing lichen planus while receiving interferon treatment due to delta hepatitis.

\section{Case}

A 31-year-old male patient presented to our infectious diseases outpatient clinic with HBsAg positivity. His only complaint was weakness. He had no underlying diseases. His physical examination yielded normal results. With his analyses, HBV DNA was negative, anti-delta total was positive, ALT was $72 \mathrm{U} / \mathrm{L}$ (upper limit $41 \mathrm{U} / \mathrm{L}$ ), platelet was $119000 / \mathrm{mm}^{3}$. Other whole blood count and biochemistry 

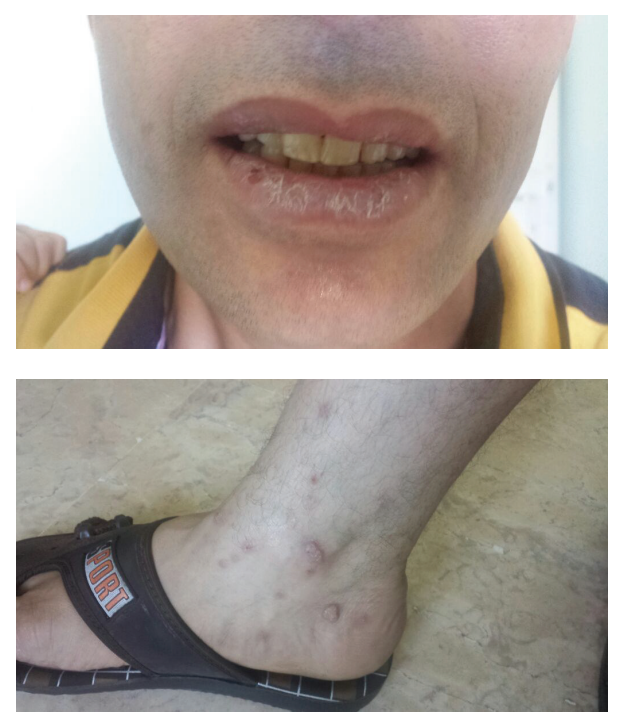

FIGURE 1: The white plaques on lip and itchy papular lesion in the foot.

results were within normal ranges. Liver biopsy was considered, but the patient refused. He was therefore started on subcutaneous pegylated interferon alfa-2a therapy at $180 \mathrm{mcg} /$ week for delta hepatitis. At month 4 of therapy, the patient developed diffuse eroded lace-like lesions in oral mucosa, white plaques on lips, and itchy papular lesions in the hands and feet (Figure 1). Lichen planus was considered by the dermatology clinic and topical treatment (mometasone furoate) was given. The lesions persisted at month 5 of therapy and biopsy samples were obtained from oral buccal mucosal lesions and interferon dose was reduced to $135 \mathrm{mcg}$. Biopsy demonstrated nonkeratinized stratified squamous epithelium; epithelial acanthosis, spongiosis, and apoptotic bodies were observed in the epidermis. In addition, lymphohistiocytic inflammatory cells were noticed especially in the style of the band dermoepidermal junction. Therefore lichen planus was considered (Figure 2). At month 6 of therapy, lesions did not improve and even progressed and interferon treatment was therefore discontinued. Over the 3-month period following treatment cessation, lesions reduced but persisted.

\section{Discussion}

LP is a major extrahepatic manifestation observed in HCV infection. Studies investigating the pathogenetic basis of the relationship between hepatitis C and LP reported that lichen planus was a disease that is associated with type 1 interferon as HCV and herpes virus infections and that LP may occur or existing lesions may worsen during therapy in diseases treated with interferon such as $\mathrm{HCV}$ infection and melanoma $[5,6]$. There are several studies on concomitant LP and $\mathrm{HCV}$. There is also a report describing a relationship between interferon and LP in the absence of $\mathrm{HCV}$ infection. Interferon alpha can induce LP, the most likely mechanism being the induction of cytokine cascade [7]. Dalekos et al. studied a total of 120 patients treated with interferon alpha for chronic
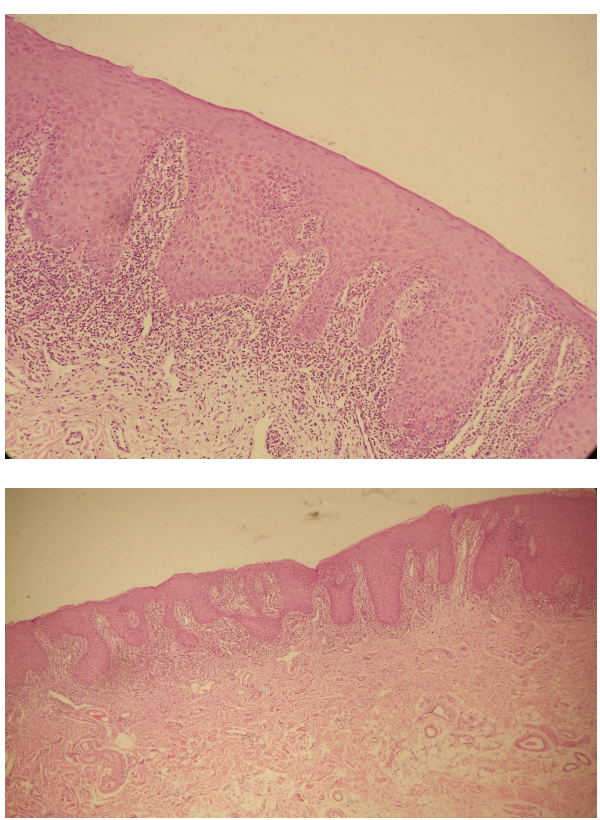

FIGURE 2: Chronic inflammatory cell infiltration in dermoepidermal junction in the buccal mucosa.

viral hepatitis (of these, 67 were treated with interferon for hepatitis B, 45 for hepatitis C, 6 for both hepatitis B and hepatitis $\mathrm{C}$, and 2 for delta hepatitis) and reported new lichen planus in 2 patients with chronic hepatitis $\mathrm{C}$ and in 1 patient with hepatitis B. Neither of the patients with delta hepatitis developed a dermatologic complication [8]. This may be due to the low number of subjects studied. Our patient is the first case of delta hepatitis in the literature developing lichen planus during interferon alpha treatment and is one of the 38 delta hepatitis patients being monitored by us. Although the first connotations of viral hepatitis and LP are HCV and extrahepatic manifestation, it should be borne in mind that LP may occur also with interferon alpha treatment in patients with delta hepatitis.

\section{Conflict of Interests}

There is no conflict of interests to declare.

\section{References}

[1] Y. Nagao and M. Sata, "Hepatitis C virus and lichen planus," Journal of Gastroenterology and Hepatology, vol. 19, no. 10, pp. 1101-1113, 2004.

[2] L. Salonen, T. Axéll, and L. Helldén, "Occurrence of oral mucosal lesions, the influence of tobacco habits an an estimate of treatment time in an adult Swedish population," Journal of Oral Pathology and Medicine, vol. 19, no. 4, pp. 170-176, 1990.

[3] Z. Ruszczak and R. A. Schwartz, "Interferons in dermatology: biology, pharmacology, and clinical applications," Advances in Dermatology, vol. 13, pp. 235-288, 1997.

[4] A. Rebora, P. Patri, E. Rampini, F. Crovato, G. Ciravegna, and P. O. Patri, "Erosive lichen planus and cirrhotic hepatitis," Italian General Review of Dermatology, vol. 15, no. 2, pp. 123-131, 1978. 
[5] J. M. de Sousa Pinto, M. Sacramento Marques, and T. Estanislau Correia, "Lichen planus and leukocytoclastic vasculitis induced by interferon alpha-2b in a subject with HCV-related chronic active hepatitis," Journal of the European Academy of Dermatology and Venereology, vol. 17, no. 2, pp. 193-195, 2003.

[6] A. H. Saval and F. C. Martinez, "Lichen planus induced by interferon- $\alpha-2 \mathrm{~B}$ therapy in a patient with cutaneous malignant melanoma," Acta Dermato-Venereologica, vol. 79, no. 5, p. 395, 1999.

[7] Z. Jadali, "Dermatologic manifestations of hepatitis C infection and the effect of interferon therapy: a literature review," Archives of Iranian Medicine, vol. 15, no. 1, pp. 43-48, 2012.

[8] G. N. Dalekos, D. Christodoulou, K. G. Kistis, E. K. Zervou, J. Hatzis, and E. V. Tsianos, "A prospective evaluation of dermatological side-effects during alpha-interferon therapy for chronic viral hepatitis," European Journal of Gastroenterology and Hepatology, vol. 10, no. 11, pp. 933-939, 1998. 


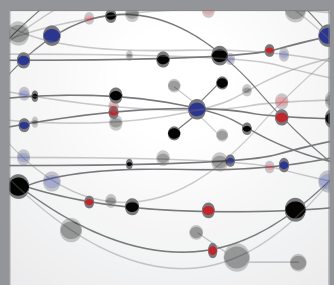

The Scientific World Journal
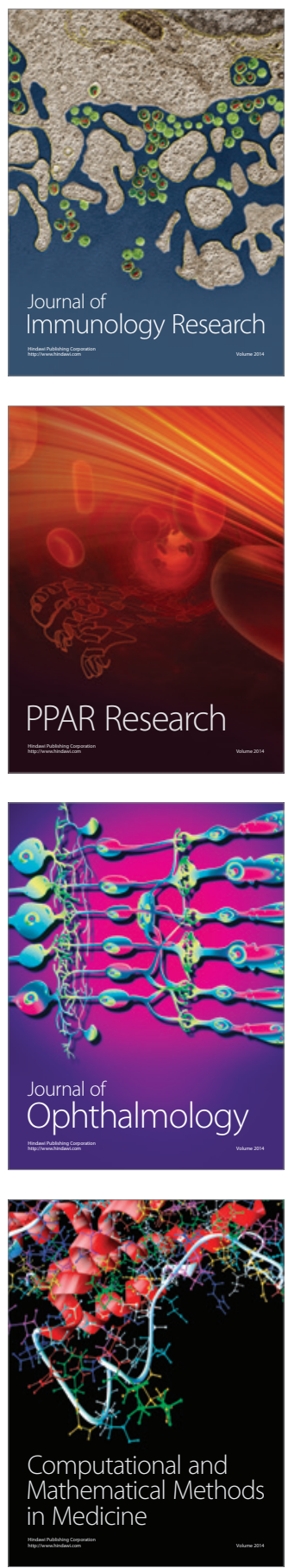

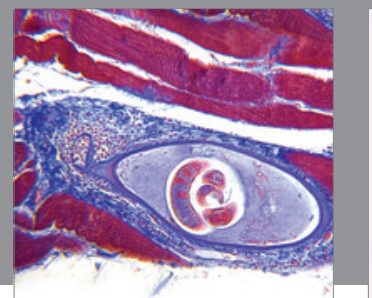

Gastroenterology

Research and Practice
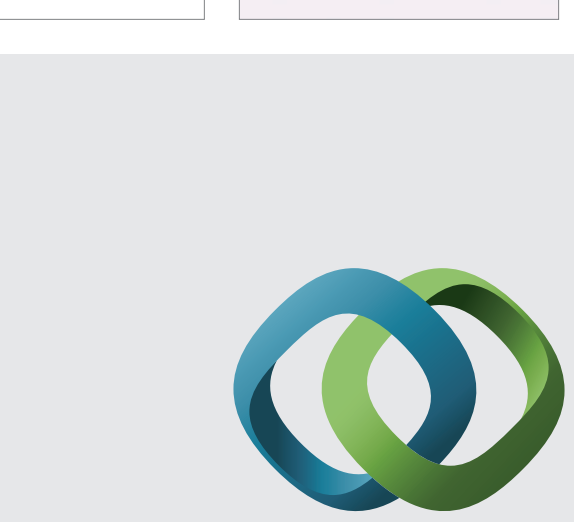

\section{Hindawi}

Submit your manuscripts at

http://www.hindawi.com
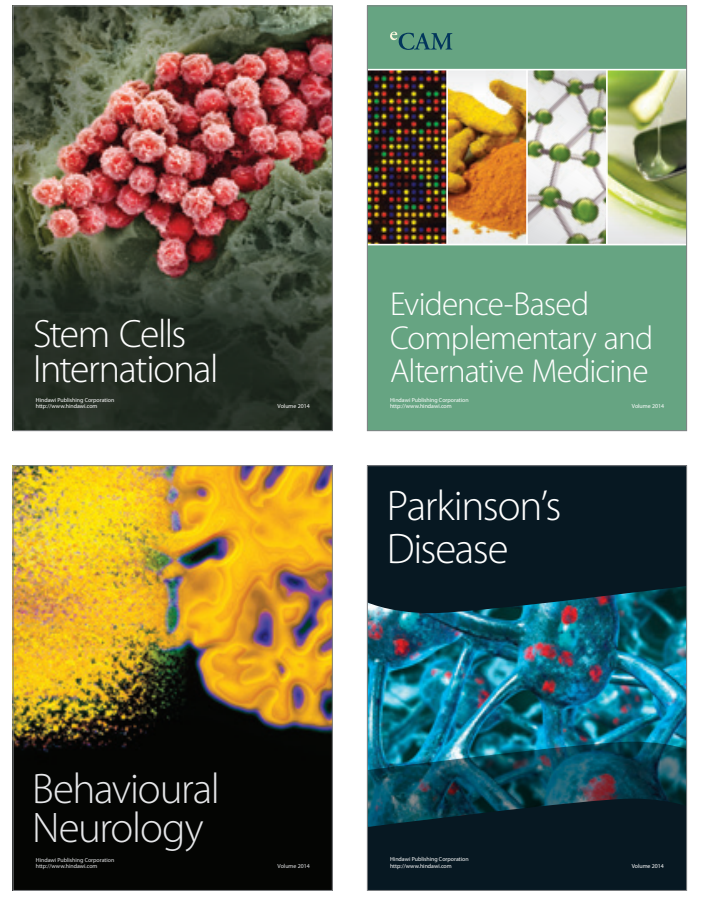
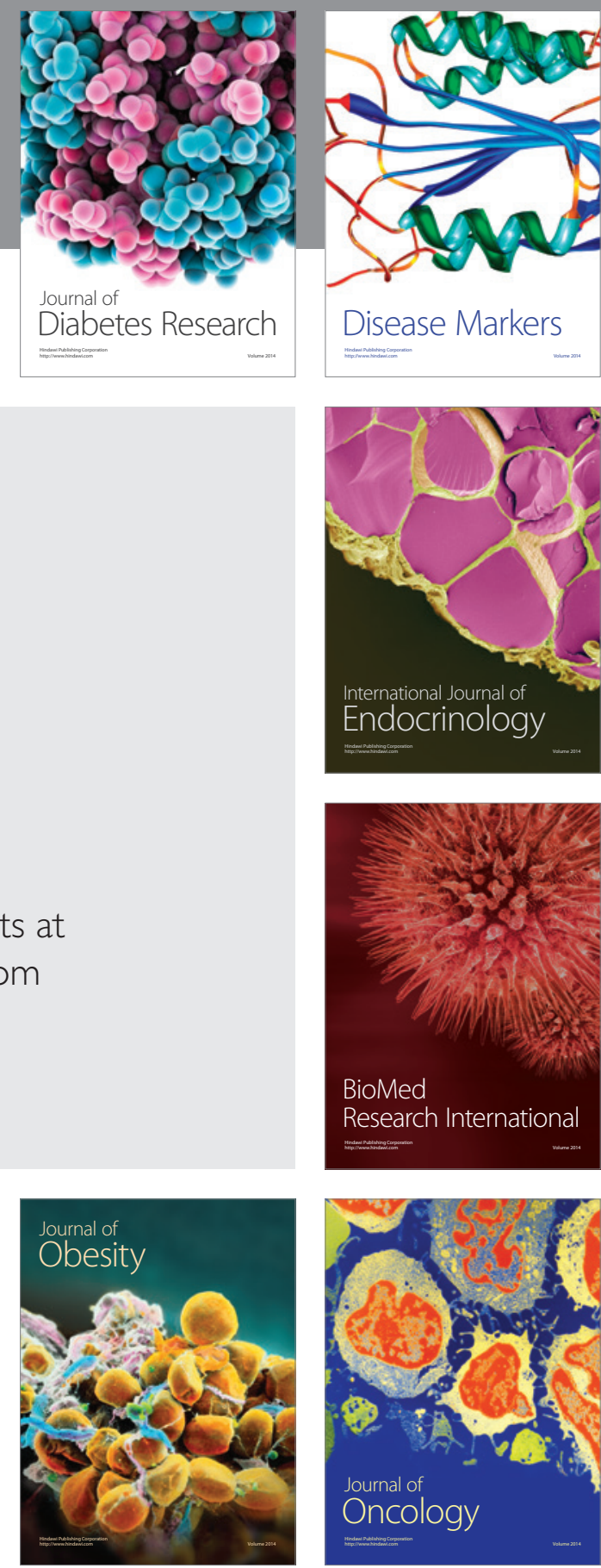

Disease Markers
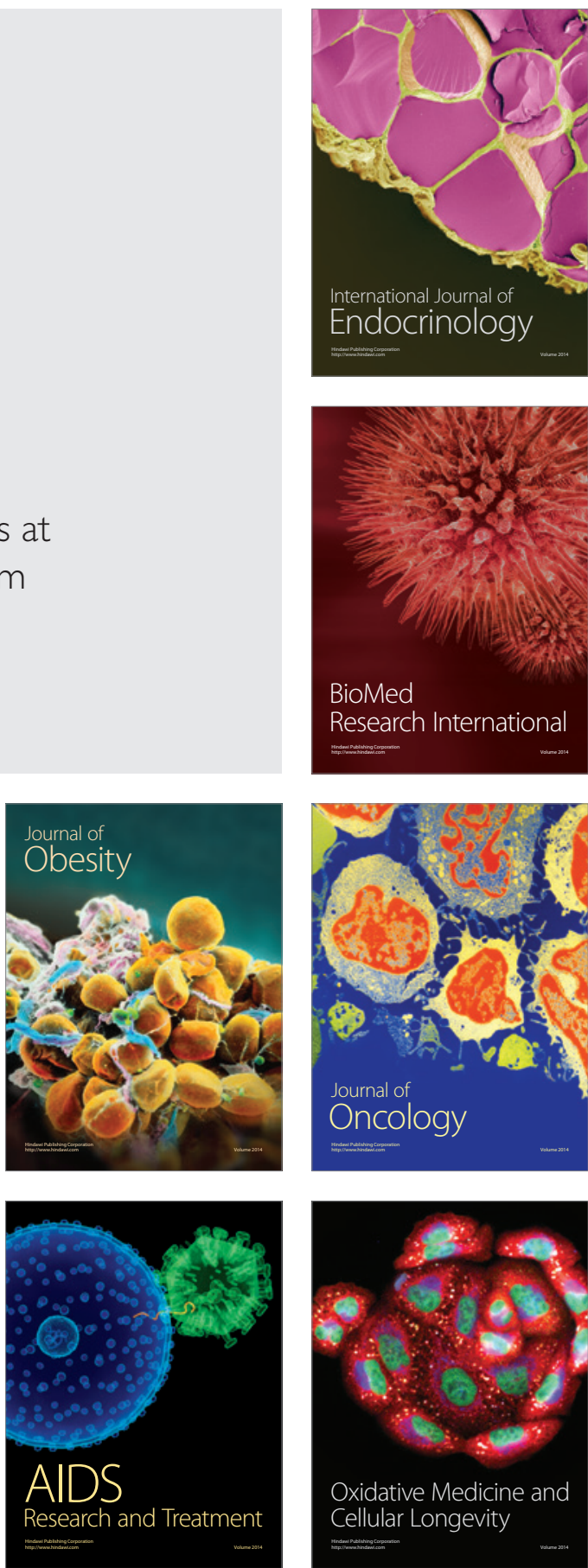